\title{
NEW TECHNICAL SOLUTIONS FOR PRECISE AND SAFE APPLICATION OF PLANT PROTECTION PRODUCTS
}

\author{
Jens Karl WEGENER \\ Julius Kühn-Institute, Institute for Application Techniques in Plant Protection, GERMANY \\ E-mail: jens-karl.wegener@julius-kuehn.de
}

Keywords: Field crop sprayer, direct injection, automation, assistance systems, pesticide application manager

\begin{abstract}
The technical development of field crop sprayers have reached a high level. Due to automation and assistance modern sprayers are able to achieve very high application quality combined with low risks for environment and operator as well as high efficacy. But, the requirement to spray plant protection products as homogeneously as possible all over the field runs out of date. Due to possibilities arising from precision farming and digitalization of agriculture the idea of site specific application moves closer to realisation. Therefore two technologies are necessary, direct injection and sensor systems for weed, pest and disease detection. Moreover, the efficacy and safety of plant protection can be still raised by looking on the whole process of plant protection, meaning to integrate planning, preparation and documentation besides the application itself. The article gives an overview about the state of the art of field crop sprayers and their technical development.
\end{abstract}

\section{INTRODUCTION}

"How to spray a tiny amount of active substance in a precise and even way all over the size of the fields?" This was the dominant question for constructing plant protection machinery in the past decades connected with the intention to avoid environmental impacts on non-target areas. Concerning this matter the technical development was mainly focussed on even lateral distribution and a reduction of drift measures by using the tools of mechanical engineering. Due to the options arising from precision farming and digitalization of agriculture the technical potentials have been enlarged a lot. Within the last few years these tools offered a lot of possibilities to improve different particular aspects of the spraying process in order to make the application of plant protection products (PPP) even more precise and to avoid associated risks. Today, the system of the application of PPP is in transition. The actual keywords of technical development in the area of field crop sprayers are "site specific application" and "automation" with regard, not only to particular aspects, but to the entire process of plant protection.

\section{FIELD CROP SPRAYERS: STATE OF THE ART}

In modern field crop sprayers a lot of functionalities have been automated so far (e.g. Herbst, 2016 \& Wegener, 2015). There is machinery available on the market having GPS-guided section control with individual nozzle switching. The proper operation of every single nozzle and its droplet spectrum can be controlled automatically as well as nozzle changes due to distance regulations near buffer zones for example. There are assistance systems controlling the optimal target distance of the boom and its adoption to the ground orientation (Horsch, 2015). Other systems are supporting trailed sprayers in order to keep the tractors track even under difficult field conditions such as slopy terrains. Along curves the application rate can be automatically adjusted within the sections of the boom in order to have a more even lateral distribution (Dammann, 2015). Latest developments even allow the compensation of an uneven longitudinal distribution caused by vibrations by using position sensors in the boom combined with nozzles operating with pulse width modulation. After application the field crop sprayer 
can be cleaned running through an automated and assisted cleaning procedure whereas the remaining quantities of PPP are minimized by using compressed air in the piping system in before. Mixing and loading have become more secure since there are Close Transfer Systems available on the market (Agrotop, n.d.), preventing the operator coming into direct contact with PPP. In order to assure best efficacy of PPP even the temperature and $\mathrm{pH}$ level of the spraying water can be monitored by sensor systems, again keeping the operator away from coming directly into contact with the PPP. Category 4 cabins according to EN 15695-1, being able to eliminate dusts, aerosols and vapors, are offered, being a substitute/supplement of personal protective equipment.

All these features mentioned so far are examples of automation of known functionalities or new types of technical solutions improving the application of PPP, saving PPP, reducing drift or enhancing the operator protection. But, all of them have in common that they have been developed by focussing more or less on a single aspect of application.

\section{SITE SPECIFIC APPLICATION}

Site specific application is one of the most important challenges in plant protection in order to save larger amount of PPP in the fields which automatically would have a positive environmental and economical impact. In order to realize this two requirements have to be satisfied from a technical point of view. First off all, there is a need to gather enough site specific information about pest and disease status of the field crops which should be treated with PPP. This is a question of sensing and information technology. Second, it needs a field crop sprayer being able to apply different kind of PPP independently from each other at the same time. This is a question of direct injection technology.

Looking on the market, there have been several attempts to realize site specific PPP treatments on the field. On Agritechnica 2015 for example the Amazone company presented the "AmaSpot" system, which was based on "greenseeker" technology and pulse width modulation, being able to implement a site specific application on basis of simple "yes/no" decision (Amazone, 2016). But, this system only works for total herbicide application on stubble fields and is not able to fulfil the requirements for PPP application under other conditions, because the sprayer has e.g. no direct injection system, allowing to mix just the amount of spray liquid which is really needed.

Other field crop sprayer prototypes with direct injection system being constructed within the last 30 years always had the following problems: too long delay times until the concentration of PPP is accomplished/depleted at the last nozzle of the boom, when the sprayer is switched on/off, insufficient dosage accuracy of PPP during spraying, problems to clean the system properly after utilization and/or inadequate area efficiency of the whole process of spraying (Krebs et al., 2015).

Also presented on Agritechnica 2015 was a new prototype of a field crop sprayer with a direct injection system that solves all the problems mentioned before. It was designed, built and tested in practice in a joint research project between the Herbert Dammann company and the Julius Kühn-Institute. The prototype which was developed is able to keep the dosing quantity within a range of $\pm 7 \%$ for any liquidly formulated PPP. It works without any delay time, can be automatically and completely cleaned after spraying and its area efficiency is comparable to conventional sprayers. It is able to apply up to three different PPP separately from each other using a separate nozzle line 
for each direct injection system (Krebs et al., 2015). Nevertheless, there are some restrictions for practical use: Solid formulated PPP can only be applied so far using conventional tank mixtures within the prototype sprayer. The possibility for section control is limited when using low dose levels of PPP $(<0,51 / \mathrm{ha})$ at slow forward speeds $(\leq 6 \mathrm{~km} / \mathrm{h}$ ). If more than one nozzle line is in use the amount of spraying water is doubled or tripled (Wegener et al., 2016). Practical tests have shown, that this may have an impact on the time needed until a PPP is taking effect. But, there was no difference concerning the efficacy of the PPP treatment during the field tests (Pohl et al., 2017).

Regarding the necessary requirements for site specific application operating sensor systems for pest and disease detection still seem to be the biggest problem. All sensors on the market so far are for weed detection. But, these known camera based solutions are either based on already mentioned "greenseeker" technology or on such systems with weed identification, which are not able to cover the whole working width of a sprayer. In this context it will be exciting to see, what new solution will be presented on Agritechnica 2017.

\section{PROCESS BASED SOLUTIONS}

Due to increasing digitalization of agriculture huge amount of data is available. This can be used in order to improve the efficacy of the whole process of plant protection. In this case, not the application itself, but also planning, preparation and documentation is included. A first attempt to interlock different steps of the process "plant protection" was presented on Agritechnica 2015: Pesticide Application Manager (PAM).

The PAM systems allows automatically to take specific distance requirements to buffer zones into consideration (Scheiber et al., 2013). Therefore, national plant protection obligations were incorporated in a web based application, which can be used in future by farm management information systems (FMS/FMIS) in practice. First FMS/FMIS which include a virtual interface to the PAM data service will be presented on Agritechnica 2017. The system works as follows: The required field data concerning field borders and surrounding structures have to be collected once and are transferred into the FMS/FMIS. When the operator decides to plan a specific pesticide application he starts to send relevant data (field coordinates, crop plant, PPP chosen, etc.) to the PAM-Service, which is calculating an application map in ISO-XML format including all specific distance requirements which have to be followed. This map is fed into the computer system of the machine and will serve as basis for the application. In a next step the operator starts the application in the fields and the machine is recording the process automatically. The calculated map and the documentation of the process can be transferred back into the FMS/FMIS after the application is done (e.g. Figure 1).

This kind of process management can help the farmer to better plan, exercise and document his plant protection application by connecting knowledge, consultancy, practice and machinery. For the future the integration of further information concerning e.g. growth stage, specific weather conditions, online application data etc. will contribute to lower the risks, save PPP and increase the economical benefit of plant protection measures. 


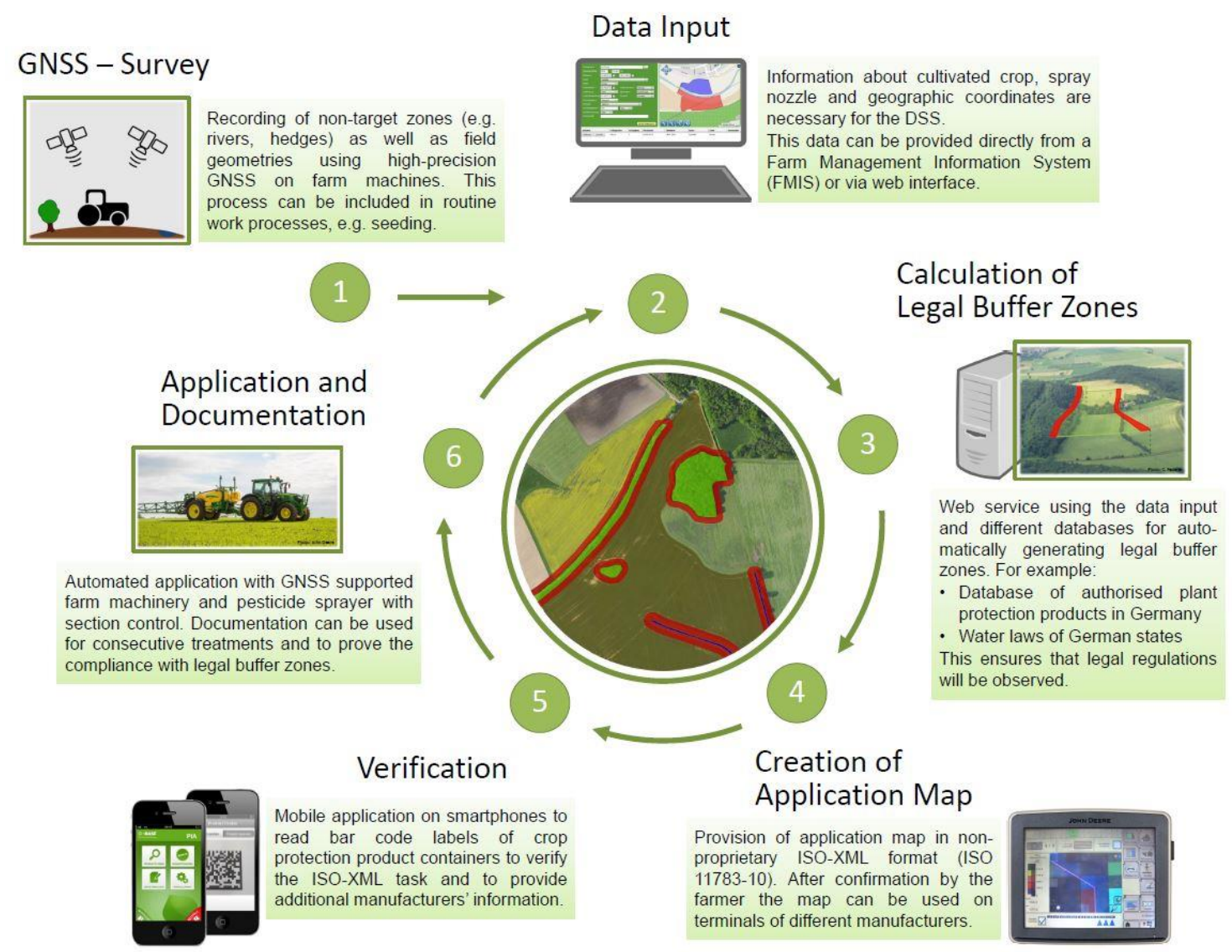

Figure 1. Decision support system of the pesticide application manager (ZEPP, 2015).

\section{CONCLUSION}

The development in plant protection technology in direction of saving PPP, lowering risks for the environment, increasing the efficacy and operator safety has reached a high standard. Modern field crop sprayers are able to spray PPP precisely with the same concentration all over the field. Due to automation nearly every feature of a sprayer can be assisted which gives the operator the opportunity to concentrate on controlling the process of application. The challenge for the future will be to overcome the equal treatment of the fields in terms of site specific application. First technical approaches are in development or even on the market. In order to further increase the efficacy of plant protection the possibilities given by precision farming and digitalization are enormously if the whole process of plant protection is in the focus of ambitions. But, a key component for future development of this approach is to find economical and practical sensor systems being able to detect weeds, pests and diseases in the fields.

\section{REFERENCES}

Agrotop (n.d.): Easy Flow closed transfer system. Retrieved August 28, 2017, from Agrotop: https://www.agrotop.com/en/easyflow/easyflow/

Amazone (2016): AmaSpot sensor nozzle system. Retrieved August 28, 2017, from Amazone: http://www.go4innovation2016.de/innovations/crop-protection-sprayers/amaspot-sensor-nozzle-system/

Dammann (2015): Curve Control Application (CCA). Retrieved August 28,2017, from Dammann: http://www.dammann-technik.de/curvescontrolapplication-cca/ 
Herbst, A. (2017): Elektronische Systeme bei Pflanzenschutzgeräten. In: Frerichs, Ludger(Ed.): Jahrbuch Agrartechnik 2016, pp. 1-8.

Horsch (2015): Boomsight - anticipating laser identification system to protect and control the spraying boom. Retrieved August 28, 2017, from Horsch: http://www.horsch.com/en/news/406/

Krebs, M., Rautmann, D., Nordmeyer, H., Wegener, J.-K. (2015): Development of a direct injection system without time lag for application of plant protection products. Landtechnik 70(6), pp. 238-252.

Pohl, J.P., Rautmann, D., Nordmeyer, H., von Hörsten, D. (2017): Site-specific application of plant protection products in Precision Farming by direct injection. Advances in Animal Biosciences 8(2), pp. $255-258$.

Scheiber, M., Kleinhenz, B., Röhrig, M. (2013): Pesticide Application Manager (PAM). EFITA-WCCACIGR Conference "Sustainable Agriculture through ICT Innovation", Turin, Italy, 24-27 June 2013, 5 pages. Retrieved August 28, 2017, from CIGR: http://www.cigr.org/GGTSPU-555dc3ff26f53e90-256781267245-7pMeBssrpUoUzUE7-LOD/Proceedings/uploads/2013/0037.pdf

Wegener, J.K., Krebs, M., Rautmann, D., Nordmeyer, H. (2016): Teilflächenspezifische Applikation von Pflanzenschutzmitteln - Stand der Technik und aktuelle Herausforderungen. In: DLG (Ed.): Proceedings of the Conference "Land.Technik für Profis 2016": Pflanzenschutz, pp. 33-46.

Wegener, J.K. (2016): Neues aus der Pflanzenschutztechnik. In: Frerichs, Ludger (Ed.): Jahrbuch Agrartechnik 2015, pp. 1-8.

ZEPP (2015): PAM - Pesticide Application Manager. Retrieved August 28, 2017, from ZEPP: http://www.zepp.info/GGTSPU-555dc3ff26f53e90-10070-1016570-6KsJuq9R5IQN33SGLOD/images/ZEPP/Projekte/PAM/Flyer_PAM_en_Druck.pdf 